\title{
A case of bovine tuberculosis in pigs in Poland - a country free from the disease
}

\author{
Marek Lipiec ${ }^{1, A, D}$, Łukasz Radulski ${ }^{1, C-D}$, Krzysztof Szulowski ${ }^{1, E-F}$ \\ ${ }^{1}$ National Veterinary Research Institute, Pulawy, Poland \\ A - Research concept and design, B - Collection and/or assembly of data, C - Data analysis and interpretation, \\ $D$ - Writing the article, E-Critical revision of the article, $F$ - Final approval of article \\ Lipiec M, Radulski Ł, Szulowski K. A case of bovine tuberculosis in pigs in Poland - a country free from the disease. Ann Agric Environ Med. \\ 2019; 26(1): 29-32. doi: 10.26444/aaem/90979
}

\begin{abstract}
Introduction. Bovine tuberculosis is a chronic contagious disease caused by Mycobacterium bovis or Mycobacterium caprae. Before widespread action conducted in Poland between 1959-1975 to combat bovine tuberculosis (BTB), about 40\% of all tuberculosis cases in pigs was caused by the bovine bacillus. At the present time, correctly carried out, long-term control of cattle has resulted in cases of bovine tuberculosis in pigs and humans being extremely rare and sporadic. In pigs, tuberculosis is most often caught in a slaughterhouse during slaughter.

Materials and method. Samples came from pigs kept on the farm. Traditional bacteriological methods on solid media (Stonebrink, LJ with pyruvate) supported by the semi-automatic, liquid indicative culture method (MGIT) and PCR test were applied in targeted studies. The GenoType Mycobacterium MTBC and CM tests (Hain Lifescience, Germany) were used to additionally confirm that isolated strains classification was used.

Results. Strains of mycobacteria were isolated from all examined pigs. Mycobacterium bovis was determined by real time PCR and Hain Genotype methods.

Conclusions. In order to effectively fight against BTB, all animals on farms should be tested, regardless of species, while the milk of suspected cows should be utilized without being used for feed. It is important to adapt the current legal regulations to the current epidemiological situation.
\end{abstract}

\section{Key words}

pigs, bovine tuberculosis, eradication

\section{INTRODUCTION}

Bovine tuberculosis (BTB) is a chronic contagious disease caused by Mycobacterium bovis or Mycobacterium caprae. Bovine tuberculosis may concern all types of domestic animals, but the disease is most common in cattle. The disease is relatively rarely found in other species of domestic and wild animals.

Before the widespread action to combat BTB conducted in 1959-1975, about $40 \%$ of all cases in pigs were caused by the bovine subspecies of mycobacteria. At the same time, this subspecies caused about $10 \%$ of cases of tuberculosis in humans [1].

Since 2009, Poland has been officially recognized as a country free from BTB, but each year there are around 20-30 outbreaks of this disease, and for this reason 100-400 cattle were eliminated from farms. In Poland, bovine tuberculosis is fought ex officio and according to the Polish disease control regulations, every year $20 \%$ of bovine animals are surveyed, with the result that that in 5 years, all animals in the country are examined [2, 3].

At the moment, correctly carried out and long-term control of cattle resulted in Mycobacterium bovis infections in pigs and humans being extremely rare and sporadic [4]. In pigs, tuberculosis is most often caught in a slaughterhouse during slaughter. Cases of the disease are also common in some species of wild animals, such as bison and wild boar, or in free range pigs in some countries $[5,6]$.

Address for correspondence: Marek Lipiec, National Veterinary Research Institute Pulawy, Poland, 24-100 Puławy, Partyzantów 57, Puławy, Poland e-mail: mlipiec@piwet.pulawy.pl

Received: 07.03.2018; accepted: 11.05.2018; first published: 15.11.2018
Typically, tuberculous lesions are described as resembling tuberculosis, but can also found in pigs in the retropharyngeal lymph nodes, and also caused by Mycobacterium avium ssp. avium. Under normal immune conditions, this mycobacterium does not present a danger for humans; however, it may pose a significant risk to patients with acquired or congenital defects of resistance, e.g. patients with $\mathrm{HIV}$ infectionor after transplantation. In laboratory tests, it is most important to confirm whether the disease was caused by the avian or bovine type of mycobacteria. There is also an additional distinction between the Mycobacterium bovis and Mycobacterium caprae strains responsible for bovine tuberculosis. Despite the small differences in the genome they have the same pathogenicity, biochemical and growth characteristics [7]. Own data indicate that nowadays about $50 \%$ of all cases of tuberculosis in cattle in Poland are caused by Mycobacterium caprae.

\section{OBJECTIVE}

The aim of the study was to accurately indicate the cause of pigs infection on a farm where BTB was also found in a herd of cattle.

\section{MATERIALS AND METHOD}

Initial tuberculin tests included all mammals on the farm (32 cattle, 9 pigs, 2 dogs and 2 cats). The laboratory study concerned samples from all positive reactors (32 cattle and 2 pigs) killed in conditions of sanitary slaughter. 
Samples of mesenteric and bronchial lymph nodes, lungs, liver and spleen from mentioned cows and pigs were tested in NVRI BTB Reference Lab. Typical tuberculous lesions were found in the mediastinal and bronchial lymph nodes of 25 cows (in 7 cases lack of BTB lesions) and 2 pigs. Microscopic preparations were prepared from all tissues and lymph nodes, which were stained using the hot Ziehl-Neelsen method.

In the culture method, all tissue samples were homogenized and decontaminated in $5.0 \%$ oxalic acid and then washed twice with a $0.85 \% \mathrm{NaCl}$ (saline), according to the Instructions of the Central Veterinary Officer. The sediments were used for direct microscopic examination, culture and for bioassay. The smears were prepared from tissues as well as sediments and stained using the Ziehl- Neelsen (ZN) method. The sediments were inoculated onto 3 Stonebrink (S), Petragnani (P) and Lowenstein- Jensen (L.J) slants. All slants were incubated at $37^{\circ} \mathrm{C}$ for $4-6$ weeks, with weekly readings. Simultaneously, samples were tested in the Mycobacteria Growth Indicator Tube (MGIT) system. All samples were prepared with MycoPrep kit (Becton Dickinson) used for the preparation of specimens containing mycobacteria, according to the manufacturer's recommendations. Pre-prepared samples were incubated for 6 weeks in an MGIT 320 incubator. Identification of the Mycobacteria species was based on multiplex real-time PCR test (Tab. 1) [8]. The GenoType Mycobacterium MTBC and CM tests (Hain Lifescience, Germany) were used to additionally confirm that isolated strains classification were used.

Table 1. Primers and probes for real-time PCR

\begin{tabular}{|c|c|c|}
\hline Name & Application & Sequence $5^{\prime}->3^{\prime}$ \\
\hline MTC_Fw & $\begin{array}{l}\text { Starter forward - } \\
\text { M.caprae }\end{array}$ & AGACCGTGCGGATCTTG \\
\hline MTC_Rv & $\begin{array}{l}\text { Starter reverse - } \\
\text { M.caprae }\end{array}$ & CATGGAGATCACCCGTGA \\
\hline $\begin{array}{l}\text { M. caprae } \\
\text { specific } \\
\text { Probe }\end{array}$ & M.caprae probe & Cyan 500- TATCGGGTACACAAAGACGA-BHQ2 \\
\hline IpqT_FW & Starter forward & ACGAATCCGGCGATGATC \\
\hline pqT_RV & Starter reverse & CGACTGCACACCTGGAA \\
\hline $\begin{array}{l}\text { pqT } \\
\text { Probe }\end{array}$ & $\begin{array}{l}\text { M.caprae, M.bovis, } \\
\text { M.bovis BCG probe }\end{array}$ & FAM-TTGGCCGGCGCCGGTT-BHQ1 \\
\hline RD1_F & Starter forward & CATCGCTGATGTGCTTGC \\
\hline RD1_Rv & Starter reverse & TGCGCCGAGCTGTATTC \\
\hline $\begin{array}{l}\text { RD1 } \\
\text { Probe }\end{array}$ & $\begin{array}{l}\text { Exclusion of presence } \\
\text { M.bovis BCG }\end{array}$ & HEX-ACACTAGCGTCAATGCGGTCA-BHQ1 \\
\hline
\end{tabular}

\section{RESULTS}

In anatomy studies, single tuberculous lesions in the mediastinal, bronchial lymph nodes and in the lung tissue were found (Fig.1). In the prepared $\mathrm{ZN}$ smears, single mycobacteria were visible in every field of view. In culture test, after 4 weeks, a large growth of acid-fast bacilli was obtained in all cases (Fig.2). The results obtained in the MGIT 320 system confirmed the presence of mycobacteria in all cases. Interpretation of multiplex real-time PCR results is presented in Table 2. PCR results clearly identified the Mycobacterium bovis species [Cyan 500 channel (-), FAM (+), HEX (+)]. GenoType CM test also gave a positive

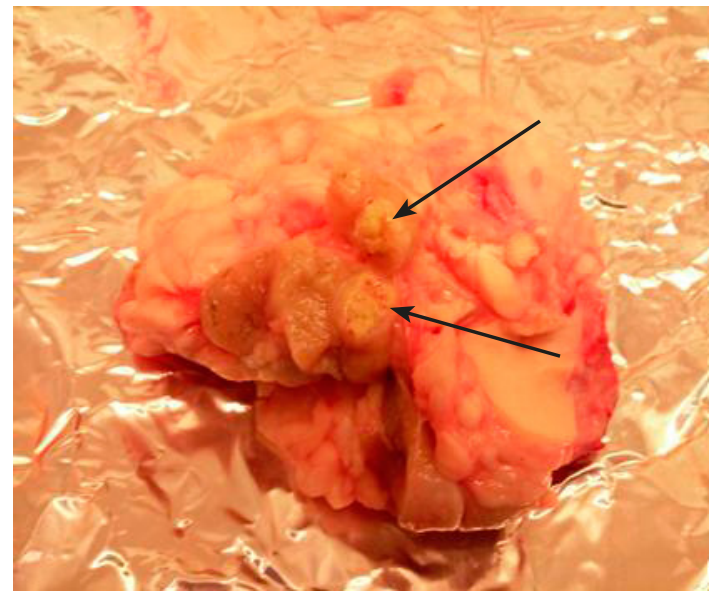

Figure 1. Tuberculous lesions in the bronchial lymph node

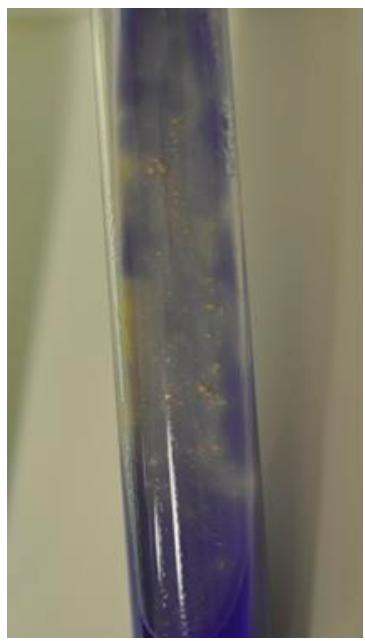

Figure 2. M.bovis colony on the Stonebrink medium

result and species of Mycobacteria have been defined as a Mycobacterium bovis.

Table 2. Real Time PCR results interpretation table

\begin{tabular}{|c|c|c|c|}
\hline \multicolumn{3}{|c|}{ Channel results analysis } & \multirow[b]{2}{*}{ Diagnostics test result } \\
\hline $\begin{array}{l}\text { Cyan } 500 \\
\text { results } \\
\text { (+ indicates } \\
\text { presence of } \\
\text { M. caprae) }\end{array}$ & $\begin{array}{c}\text { FAM } \\
\text { (+ indicates } \\
\text { presence of M. } \\
\text { bovis, M. bovis } \\
\text { BCG or M. caprae) }\end{array}$ & $\begin{array}{c}\text { HEX } \\
\text { (- indicates } \\
\text { presence of M. bovis } \\
\text { BCG if positive in } \\
\text { FAM channel) }\end{array}$ & \\
\hline+ & + & + & M. caprae present \\
\hline- & + & + & M. bovis present \\
\hline- & + & - & M. bovis $B C G$ present \\
\hline - & - & + & $\begin{array}{l}\text { MTC member other than } \\
\text { M. caprae, } M \text {. bovis, } M \text {. } \\
\text { bovis BCG or M. microti }\end{array}$ \\
\hline- & - & - & $\begin{array}{l}\text { Invalid result - test must } \\
\text { be repeated }\end{array}$ \\
\hline
\end{tabular}

\section{DISCUSSION}

In 2009, Poland was declared a country free of bovine tuberculosis. This does not mean that outbreaks of this 
disease are no longer occur in the country. In 2016, there were 33 outbreaks of the disease in cattle, whereas in 2017 there were only 20 , and due to positive tuberculin tests, respectively, 383 and 90 animals of the cattle species were eliminated. It seems that in a country with a cattle population of around 5.5 million, this is a very good result. In Poland during the period 1948-1959, when tuberculosis in cattle was widespread (about $30 \%$ of the bovine population were considered ill), almost half of all cases of tuberculosis in pigs were caused by Mycobacterium bovis [3]. The fight against bovine tuberculosis in Poland is facilitated by the fact that there are no sources of disease among wild animals, such as badgers in the UK [9]. However, among the wild animals in Poland in 2010-2017, only a dozen outbreaks of bovine tuberculosis in European bisons and wild boars (without contact with cattle or breeding pigs) were noted in the Bieszczady Mountain area [6].

The reduction of tuberculosis in cattle, together with the change in the pig farming system, caused the reduction of M.bovis infections in this animal species. The described case of bovine tuberculosis in domestic pig (Sus scrofa $f$. domestica) caused by Mycobacterium bovis is the only one described in Poland over the last 15 years. However, such cases are still recorded in pigs reared under environmental conditions, usually in the Mediterranean region, but also in other European countries. In 2004, in Great Britain, pigs became an animal species with the highest frequency of confirmed BTB infections, not including cattle. Of the total 748 samples collected from domestic and wild boar between 2004-2010, in 85 cases M.bovis and in 121 M. avium were found. Almost all M. bovis-infected pigs originated from farms in the South-West and West-Midland regions of England. In the majority of cases, the same strains of $M$. bovis were found in pigs and cattle, despite the fact that direct contact between these species was rarely observed. In Scotland during the same period, $M$. bovis infection was identified in 116 cats, 7 dogs, 34 llamas, 133 alpacas, 35 goats, 24 sheep and 85 pigs[10]. This proves that the pig is highly susceptible to M. bovis infection [11]. In Italy (Sicily), 119 black pigs were tested and slaughtered in a slaughterhouse. These pigs came from regions of Sicily characterized by a high percentage of cattle suffering from BTB. In 4 pigs, M. bovis bacilli were detected [12]. In Spain, 129 samples of pigs tissues from farms on which bovine tuberculosis was previously diagnosed were tested. 59 (45.7\%) of the 129 samples were classified as positive. In 8 samples in which no tuberculous lesions were detected, the presence of MTC was detected [13].

In order to determine the mycobacterium strain in the most productive swine area in Argentina, 143 porcine isolates of $M$. bovis were tested by spoligotyping. 135 (94\%) of them showed identical patterns as in infected cattle. This testifies to the epidemiological link between these species [14]. 4 years later, $250 \mathrm{M}$. bovis isolates from slaughtered pigs were subjected to similar tests. Some forms have been shown to occur only in pigs without being found in cattle. This demonstrates the potential of pigs as a vector for disease transmission to cattle [15].

A much more serious situation exists in the field of pigs BTB in some African countries. Research carried out in Uganda indicates the occurrence of $M$. bovis in slaughter pigs. One in 50 slaughter pigs (2.0\%) with suspected lesions in mesenteric lymph nodes was M.bovis infected [16]. The data obtained during the examination of pigs in Ethiopia indicate that they can not only be a source of bovine bacillus, but also the human type bacillus for other animal species and humans [17].

Currently, contact of pigs with wild birds or poultry on small farms results in the presence of tuberculous lesions, usually in the parotid lymph nodes. Among mycobacteria, Mycobacterium avium subspecies type 1 and subspecies type 2 were predominantly identified. The application of measures aimed at controlling $M$. bovis in cattle led to a significant reduction of incidence of infection in pigs and other domestic animals. At present, only sporadic cases of infection in pigs occur, as in the presented case. In the last 15 years, there have been no further cases of BTB in breeding pigs in Poland.

Nowadays, an additional difficulty in combating BTB is the fact that the Polish Act of 11 March 2004 on animal health protection and combating infectious animal diseases, translates the term 'bovine tuberculosis' as an infection or disease caused by M.bovis only in cattle species, but not in other animals [1].Therefore, there is no legal basis for investigating e outbreaks of BTB in various other species of domestic and wild animals as well as the inability to their purchase by the governments. The breeder has the option of reimbursing costs only as a possible reward from the Veterinary Inspection, and not in the form of a priced, real value of the suffering animals. This may relates to horses, pigs, sheep, goats on the farm, and accompanying animals, i.e. dogs and cats.

It is also important to take into account in the amended legislation the possibility of developing the disease by Mycobacterium caprae. The veterinary inspection, on receiving a result from the reference laboratory, described as an isolate of this strain mycobacterium, has no basis on which to fight the disease because the rules apply only Mycobacterium bovis as the causative agent of the disease, and limited to one species (cattle). These inconveniences require urgent changes in the Polish legislation in the field of combating BTB. Many cases of BTB can be dangerous as the slaughter of animals of this species can be carried out on the farm of the breeder, where visual and postmortem inspections of the carcass by the veterinarian are not carried out. In contrast, cases of tuberculosis in cattle can be diagnosed at the slaughterhouse, if they have not been previously identified during an earlier planned tuberculin test, using bovine tuberculin (single test) or both bovine and avian tuberculin (comparative tests).

According to the directive of the Minister of Agriculture and Rural Development of 23 November 2004 [1] on the fight against bovine tuberculosis, the District Veterinary Officer forbids feeding with milk from animals diagnosed with bovine tuberculosis, unless: the milk has been treated to inactivate tuberculosis bacilli, or only animals from the same farm will be fed with milk. It seems that such milk should be utilized and not be used for feeding animals, otherwise it exposes the health and life of not only pigs, but also people, on the infected farm

\section{REFERENCES}

1. Sobiech T. Gruźlica zwierząt. Państwowe Wydawnictwo Rolnicze i Leśne, Warszawa, 1975.

2. Rozporządzenie Ministra Rolnictwa i Rozwoju Wsi z dnia 23 listopada 2004 r. w sprawie zwalczania gruźlicy bydła (Dz. U. z dnia 6 grudnia 2004 r.). 
3. Instrukcja Głównego Lekarza Weterynarii Nr GIWpr-022010-8/2016, z dnia 8 lutego 2016 r. w sprawie postępowania przy podejrzeniu, potwierdzeniu i zwalczaniu w stadzie bydła oraz przy prowadzeniu badań kontrolnych gruźlicy bydła.

4. LoBue PA, Enarson DA, Thoen CO. Tuberculosis in humans and animals: an overview. Int Tuberc Lung Dis. 2010; 14(9): 1075-1078.

5. Krajewska M, Lipiec M, Zabost A, Augustynowicz-Kopeć E, Szulowski K. Bovine tuberculosis in a wild boar (Sus scrofa) in Poland. J Wildl Dis. 2014; 50(4): 1001-1002. doi: 10.7589/2013-07-187.

6. Krajewska M, Zabost A, Welz M, Lipiec M, Orłowska B, Anusz K, Brewczyński P, Augustynowicz-Kopeć E, Szulowski K, Bielecki W, Weiner M. Transmission of Mycobacterium caprae in a herd of European bison in the Bieszczady Mountains, Southern Poland. Eur J Wildlife Res. 2015; 61(3): 429-433.

7. Javed MT, Aranaz A, de Juan L, Bezos J, Romero B, Alvarez J, Lozano C, Mateos A, Domínguez L. Improvement of spoligotyping with additional spacer sequences for characterization of Mycobacterium bovis and $\mathrm{M}$. caprae isolates from Spain. Tuberculosis (Edinb). 2007; 87(5): 437-445.

8. Reddington K, O'Grady J, Dorai-Raj S, Niemann SA. Novel Multiplex Real-Time PCR for the identification of mycobacteria associated with zoonotic tuberculosis. PLoS ONE. 2011; 6(8): 1-8.

9. Harris KA, Brunton L, Brouwer A, Garcia MP, Gibbens JC, Smith NH, Upton PA. Bovine TB infection status in cattle in Great Britain in 2015. Vet Rec. 2017; 180(7): 170-175.

10. Broughan JM, Downs SH, Crawshaw TR, Upton PA, Brewer J, CliftonHadley RS. Mycobacterium bovis infections in domesticated non-bovine mammalian species. Part 1: Review of epidemiology and laboratory submissions in Great Britain 2004-2010. Vet J. 2013; 198(2): 339-345.
11. Bailey SS, Crawshaw TR, Smith N, Palgrave CJ. Mycobacterium bovis infection in domestic pigs in Great Britain. Vet J. 2013; 198(2): 346-351.

12. Di Marco V, Mazzone P, Capucchio MT, Boniotti MB, Aronica V, Russo M, Fiasconaro M, Cifani N, Corneli S, Biasibetti E, Biagetti M, Pacciarini ML, Cagiola M, Pasquali P, Marianellif C. Epidemiological significance of the domestic black pig (Sus scrofa) in maintenance of bovine tuberculosis in Sicily. J Clin Microbiol. 2012; 50(4): 1209-1218.

13. Cardoso-Toset F, Luque I, Carrasco L, Jurado-Martos F, Risalde MÁ, Venteo Á, Infantes-Lorenzo JA, Bezos J, Rueda P, Tapia I, Gortázar C, Domínguez L, Domínguez M, Gomez-Laguna J. Evaluation of five serologic assays for bovine tuberculosis surveillance in domestic freerange pigs from southern Spain. Prev Vet Med. 2017; 1(137): 101-104.

14. BarandiaranS, Martınez Vivot M, Moras EV, Cataldi AA. Mycobacterium bovis in swine: spoligotyping of isolates from Argentina. Vety Med Int. 2011; 1-6, doi: 10.4061/2011/979647.

15. Barandiaran S, M. Martínez Vivot M, Pérez AM, Cataldi AA, Zumarraga MJ. Bovine tuberculosis in domestic pigs: Genotyping and distribution of isolates in Argentina. Res Vet Sci. 2015; 44-50, doi: 10.1016/j.rvsc.2015.09.013.

16. Muwonge A, Johansen TB, Vigdis E, Godfroid J, Olea-Popelka F, Biffa D, Skjerve E, Djønne B. Mycobacterium bovis infections in slaughter pigs in Mubende district, Uganda: a public health concern. BMC Vet Res. 2012; 8: 168, doi: 10.1186/1746-6148-8-168.

17. Arega SM, Conraths FJ, Gobena A. Prevalence of tuberculosis in pigs slaughtered at two abattoirs in Ethiopia and molecular characterization of Mycobacterium tuberculosis isolated from tuberculous-like lesions in pigs. BMC Vet Res. 2013; 9: 97, doi: 10.1186/1746-6148-9-97. 